\title{
KECENDERUNGAN PENDERITA RETINOPATI DIABETIK
}

\author{
${ }^{1}$ Venesia Pengan \\ ${ }^{2}$ Harry J.G. Sumual \\ ${ }^{2}$ Laya M. Rares
}

\author{
${ }^{1}$ Kandidat Skripsi Fakultas Kedokteran Universitas Sam Ratulangi Manado \\ ${ }^{2}$ Bagian Ilmu Kesehatan Mata BLU RSUP Prof. Dr. R.D. Kandou - Manado
}

\begin{abstract}
One of the complications of diabetes is microvascular complications of retinopathy in the eye is that if it continues to be a cause of blindness. The incidence of diabetic retinopathy continues to increase with the increase in people with diabetes with uncontrolled blood sugar. Blindness due to diabetic retinopathy is a health problem that look out world because of blindness will decrease the patient's quality of life and productivity which ultimately led to the social burden to society. The purpose of this study was to determine the tendency of patients with diabetic retinopathy.

This is a descriptive study to examine the data of diabetic retinopathy patients in ophthamology community health center. It was found that the number of patients with diabetic retinopathy in 2012 is 34 people and in 2013 amounted to 44 people. An increasing number of people with diabetic retinopathy in 2013 amounted to 10 people or in a precentage of an increase in the number of patients is as much as $29.41 \%$. Number of patients with diabetic retinopathy men in 2012 was 12 and in 2013 to 15 so as to increase by $25 \%$ and the number of women in 2012 was 22 and in 2013 was 29, an increase in patients is as much as $31.81 \%$. Based on the group of age, the amount of patients in 2013 in the group of 20-40 years is 2 persons, 41-60 years amounted to 20 people, $>60$ amounted to 14 people, while in 2013 the number of people in the group of 20-40 years became 3 persons, 41-60 years to 30 people and $>60$ became 11 people. Increased number of patients with diabetic retinopathy in 2013 with the total of 10 persons and a precentage of $29.41 \%$.
\end{abstract}

Keywords: diabetic mellitus, diabetic retinopaty.

\begin{abstract}
Abtrak: Salah satu komplikasi dari DM adalah komplikasi mikrovaskuler pada mata yaitu retinopati yang jika terus berlanjut akan menjadi penyebab kebutaan. Angka kejadian retinopati diabetik terus meningkat dengan peningkatan penyandang DM disertai gula darah tidak terkontrol. Kebutaan akibat retinopati diabetik ini menjadi masalah kesehatan yang diwaspadai dunia karena kebutaan akan menurunkan kualitas hidup dan produktivitas penderita yang akhirnya menimbulkan beban sosial bagi masyarakat. Tujuan penelitian ini untuk mengetahui adanya kecenderungan penderita retinopati diabetik. Penelitian ini bersifat deskriptif dengan meneliti data-data penderita retinopati diabetik di Balai Kesehatan Mata Masyarakat. Didapatkan bahwa jumlah penderita pasien retinopati diabetik pada tahun 2012 sebanyak 34 orang dan tahun 2013 berjumlah 44 orang. Peningkatan jumlah penderita retinopati diabetik di tahun 2013 berjumlah 10 orang atau dalam persentase terjadi peningkatan jumlah penderita sebanyak 29,41\%. Jumlah penderita retinopati diabetik laki-laki pada tahun 2012 adalah 12 orang dan tahun 2013 menjadi 15 orang sehingga terjadi peningkatan sebanyak 25\% dan jumlah perempuan pada tahun 2012 adalah 22 orang dan pada tahun 2013 adalah 29 orang, peningkatan penderita sebanyak 31,81\%. Berdasarkan kelompok umur jumlah penderita pada tahun 2012 dengan kelompok umur 20-40 tahun berjumlah 2 orang, 41-60 tahun berjumlah 20 orang, >60 berjumlah 14 orang sedangkan pada tahun 2013 jumlah penderita dengan kelompok umur 20-40 tahun menjadi 3 orang, 41-60 tahun 30 orang dan>60 tahun menjadi 11 orang. Terjadi peningkatan jumlah penderita retinopati diabetik di tahun 2013 dengan jumlah 10 orang dengan presentase 29,41\%.
\end{abstract}

Kata kunci: diabetes melitus, retinopati diabetik. 
Diabetes melitus (DM) adalah penyakit degeneratif kronik yang memiliki angka morbiditas dan mortalitas tertinggi di dunia. ${ }^{1}$ World Health Organization (WHO) melaporkan bahwa Indonesia berada di urutan keempat negara yang jumlah penyandang DM terbanyak. Jumlah ini akan mencapai 21,3 juta pada tahun 2013. ${ }^{2}$

Salah satu komplikasi dari DM adalah komplikasi mikrovaskular pada mata yaitu retinopati yang jika terus berlanjut akan menjadi penyebab kebutaan. ${ }^{3}$ Retinopati diabetik merupakan penyebab kebutaan terbesar di Amerika Serikat, prevalensi retinopati diabetik sendiri di Amerika sebesar 4,1juta orang. Penelitian epidemiologis di Amerika, Australia, Eropa dan Asia melaporkan bahwa jumlah penderita retinopati diabetik akan meningkat dari 100,8 juta pada tahun 2012 menjadi 154,9 juta pada tahun 2030 dengan 30\% di antaranya terancam kebutaan. The Diab Care Asia 2008 Study dengan melibatkan 1.785 penderita DM pada 18 pusat kesehatan primer dan sekunder di Indonesia melaporkan bahwa 42\% penderita DM akan mengalami komplikasi retinopati dan 6,4\% diantaranya merupakan retinopati DM proliferatif., ${ }^{4,5}$

Faktor resiko yang mempengaruhi seorang penyandang DM menderita gangguan retina yaitu lamanya seseorang menyandang DM, ketergantungan insulin pada DM tipe 2, nefropati dan hipertensi. ${ }^{1}$ Selain itu, pubertas dan kehamilan dapat mempercepat progresivitas retinopati diabetik. ${ }^{7}$ Hampir semua penyandang DM tipe 1 akan mengalami retinopati diabetik dengan berbagai derajat setelah 20 tahun dan 60\% pada DM tipe $2{ }^{6}$

Kebutaan akibat retinopati diabetik menjadi masalah kesehatan yang diwaspadai di dunia karena kebutaan akan menurunkan kualitas hidup dan produktivitas penderita yang akhirnya menimbulkan beban sosial masyarakat. Masalah utama dalam penanganan retinopati diabetik adalah keterlambatan diagnosis karena sebagian besar penderita pada tahap awal tidak mengalami gangguan penglihatan. ${ }^{1}$

Dokter umum di pelayanan kesehatan primer memegang peranan penting dalam deteksi dini retinopati diabetik, penatalaksanaan awal, menentukan kasus rujukan ke dokter spesialis mata dan menerimanya kembali. Apabila peranan tersebut dilaksanakan dengan baik, maka risiko kebutaan akan menurun hingga mencapai lebih dari $90 \%{ }^{1}$

Berdasarkan uraian di atas, dapat diketahui bahwa dengan semakin meningkatnya prevalensi penyakit DM maka risiko mengalami komplikasi retinopati diabetik akan semakin meningkat pula. Sejalan dengan hal tersebut maka gangguan fungsi penglihatan seperti penurunan ketajaman penglihatan bahkan kebutaan akan semakin meningkat dan membawa dampak berupa beban sosial. Dengan masalah tersebut perlu diadakan penelitian untuk mengkaji seberapa banyak penderita retinopati diabetik yang berkunjung di Balai Kesehatan Mata Masyarakat (BKMM) Manado periode Januari-Juni 2012 dan Januari-Juni 2013 agar dapat mengetahui prevalensi dan kecenderungan peningkatan penderita retinopati diabetik.

\section{RUMUSAN MASALAH}

Dengan memperhatikan latar belakang masalah di atas, dapat dirumuskan masalah penelitian yaitu "Apakah ada kecenderungan peningkatan penderita retinopati diabetik?”

\section{METODE PENELITIAN}

Penelitian yang dilakukan bersifat deskriptif dengan meneliti data-data penderita Diabetik Retinopati di Balai Kesehatan Mata Masyarakat (BKMM). Dalam hal ini data yang diambil adalah jumlah Penderita Retinopati Diabetik yang berkunjung di Balai Kesehatan Mata Masyarakat periode Januari-Juni 2012 dan Januari-Juni 2013. Setelah data dikumpulkan, data akan diolah dengan menggunakan Microsoft Excel dan di presentasikan dalam bentuk tabel dan bagan.

Definisi operasional yang dilakukan :Retinopati diabetik: kelainan-kelainan retina (retinopati) yang ditemukan pada penderita Diabetes Melitus (DM). Kelompok umur: satuan waktu yang mengukur 
waktu keberadaan seseorang yang dihitung sejak orang tersebut dilahirkan yang tertera pada status/rekam medik pasien. Kelompok umur: 20-40 tahun, 41-60 tahun, >60 tahun. Jenis kelamin: Jenis kelamin dinyatakan dalam laki-laki dan perempuan. Periode: waktu saat pasien melakukan pemeriksaan di Balai Kesehatan Mata Masyarakat. Periode yang akan diteliti adalah JanuariJuni 2012 dan Januari-Juni 2013.

\section{HASIL PENELITIAN}

Berdasarkan hasil penelitian yang dilaksanakan, pada periode Januari-Juni 2012 ada 34 penderita retinopati diabetik dan pada periode Januari-Juni 2013 berjumlah 44 penderita.

Tabel 1. Distribusi jumlah penderita berdasarkan bulan dan tahun

\begin{tabular}{lllllllll}
\hline \multirow{2}{*}{ Tahun } & \multicolumn{7}{c}{ Bulan } \\
\cline { 2 - 8 } & Januari & Februari & Maret & April & Mei & Juni & Total & Persentase \\
\hline $\mathbf{2 0 1 2}$ & 3 & 6 & 20 & 1 & 2 & 2 & 34 & 100,00 \\
$\mathbf{2 0 1 3}$ & 15 & 8 & 6 & 3 & 4 & 8 & 44 & 129,41 \\
\hline
\end{tabular}
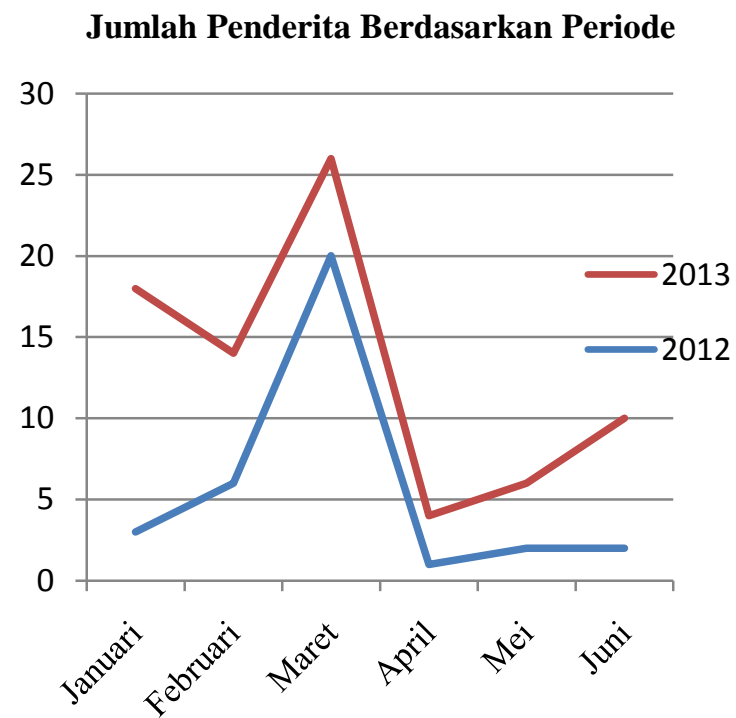

Gambar 1. Bagan jumlah penderita berdasarkan periode

Berdasarkan Tabel 1 Didapatkan bahwa jumlah penderita pasien retinopati diabetik padat ahun 2012 sebanyak 34 orang dan tahun 2013 berjumlah 44 orang. Peningkatan jumlah penderita retinopati diabetik di tahun 2013 berjumlah 10 orang atau dalam persentase terjadi peningkatan jumlah penderita sebanyak 29,41\%.
Tabel 2. Distribusi jumlah penderita berdasarkan jenis kelamin

\begin{tabular}{llll}
\hline $\begin{array}{l}\text { Jenis } \\
\text { Kelamin }\end{array}$ & $\mathbf{2 0 1 2}$ & $\mathbf{2 0 1 3}$ & $\begin{array}{l}\text { Persentase } \\
\text { Kenaikan (\%) }\end{array}$ \\
\hline Laki-laki & 12 & 15 & 25,00 \\
Perempuan & 22 & 29 & 31,81 \\
Total & 34 & 44 & \\
\hline
\end{tabular}

Perbedaan Jumlah Penderita Berdasarkan Jenis Kelamin

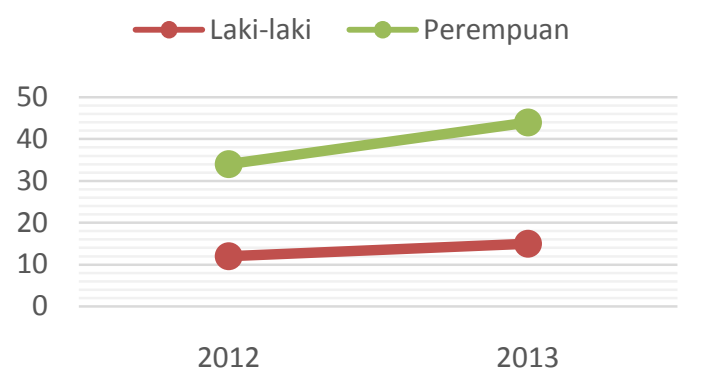

Gambar 2. Bagan perbedaan jumlah penderita berdasarkan jenis kelamin

Mengacu pada Tabel 2. Jumlah penderita retinopati diabetik laki-laki pada tahun 2012 adalah 12 orang dan tahun 2013 menjadi 15 orang, sehingga terjadi 
peningkatan sebanyak 25\% dan jumlah perempuan pada tahun 2012 adalah 22 orang dan pada tahun 2013 adalah 29 orang, peningkatan penderita retinopati diabetik sebanyak 31,81\%.

Tabel 3. Distribusi jumlah penderita berdasarkan kelompok umur

\begin{tabular}{llll}
\hline $\begin{array}{l}\text { Kelompok } \\
\text { Umur } \\
\text { (tahun) }\end{array}$ & $\mathbf{2 0 1 2}$ & $\mathbf{2 0 1 3}$ & $\begin{array}{l}\text { Persentase } \\
\text { Kenaikan } \\
\text { (\%) }\end{array}$ \\
\hline $20-40$ & 2 & 3 & 50,0 \\
$41-60$ & 20 & 30 & 50,0 \\
$>60$ & 12 & 11 & $-8,3$ \\
Total & 34 & 44 & \\
\hline
\end{tabular}

Jumlah penderita berdasarkan kelompok umur

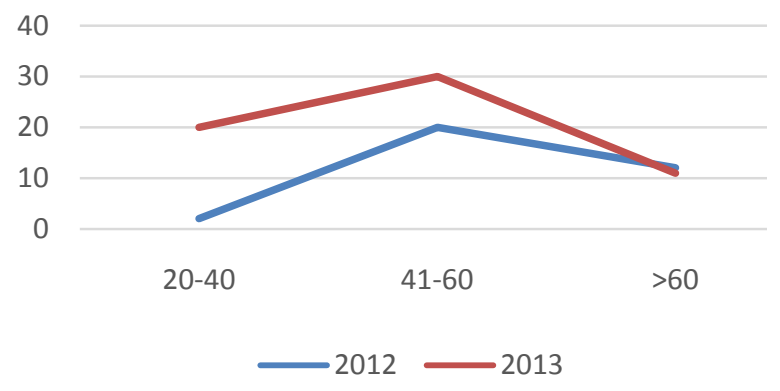

Gambar 3. Bagan jumlah penderita berdasarkan kelompok umur

Tabel 3 Memperlihatkan bahwa jumlah penderita pada tahun 2012 dengan kelompok umur 20-40 tahun berjumlah 2 orang, 41-60 tahun berjumlah 20 orang, $>60$ berjumlah 12 orang sedangkan pada tahun 2013 jumlah penderita dengan kelompok umur 20-40 tahun menjadi 3 orang, 41-60 tahun menjadi 30 orang dan $>60$ tahun menjadi 11 orang. Dari tabel ini kita bisa mendapatkan peningkatan penderita pada kelompok umur 20-40 dan kelompok umur 41-60 tahun sebesar 50\% tetapi terjadi penurunan sebesar $8,3 \%$ pada kelompok umur $>60$ tahun.

\section{SIMPULAN}

Dari hasil penelitian ini dapat disimpulkan bahwa:

1. Peningkatan penderita pada dari periode Januari-Juni2012 ke Januari-Juni 2013 yaitu $29,41 \%$.

2. Persentase peningkatan pada jenis kelamin perempuan lebih tinggi dari pada laki-laki yaitu sebesar 31,81\%.

3. Ada peningkatan pada kelompok umur 20-40 tahun dan 40-60 tahun yaitu sebesar 50\% sedangkan pada kelompok umur $>60$ tahun terjadi penurunan sebesar $8,3 \%$.

\section{SARAN}

1. Perlu adanya penyuluhan kepada masyarakat tentang bahaya dan resiko dari DM terutama retinopati diabetik serta cara pencegahannya.

2. Diperlukan penelitian lebih besar dan lanjut untuk mengetahui prevalensi penderita retinopati diabetik dan kecenderungan peningkatannya.

3. Pada penderita retinopati diabetik dapat untuk segera dilakukan penanganan untuk memperkecil resiko kebutaan dan komplikasi lainnya lagi.

\section{DAFTAR PUSTAKA}

1. Sitompul R. Retinopati Diabetik. Journal of the Indonesian Medical Association. 2011 Agustus; 61(8).

2. Wild S, Roglic G, Green A, Sicree R, King $\mathrm{H}$. Global prevalence of diabetes: estimates for the year 2000 and projections for 2030 . Diabetes Care. 2004; 27:1047-53.

3. Noble J, Chaudhary V. Diabetic retinopathy. CMAJ. 2010; 182(15):1646.

4. Fong DS, Aiello L, Gardner TW, King GL, Blankenship G, Cavallerano JD. Diabetic retinopathy. Diabetes Care. 2003; 26(Suppl1):S99-102.

5. Kempen J, O'Colmain B, Leske M, Haffner S, Klein R, Moss S, et al. The Prevalence of Diabetic Retinopathy among Adults in the United States. Archive of Opthalmology. 2004 April; 122(4): p. 552-563.

6. Nasution K. Deteksi Dini Retinopati Diabetik. Journal of Indonesian Medical 
Pengan, Sumual, Rares; Kecenderungan Penderita Retinopati Diabetik

Association. 2011 Agustus; 61(8): p. 307-

309.

7. Fong DS, Aiello L, King GL, Blankenship G, Cavallerano JD, Ferris FL. Retinopathy in diabetes. Diabetes Care. 2004;27 (Suppl1):S84-7. 